\title{
The Digital Business Architect - Towards Method Support for Digital Innovation and Transformation
}

\author{
Matthias Wißotzki ${ }^{1}$ and Kurt Sandkuhl ${ }^{1}$ \\ University of Rostock, Chair of Business Information Systems, Albert-Einstein-Str. 22, \\ 18059 Rostock, Germany \\ \{matthias.wissotzki, kurt.sandkuhl\}@uni-rostock.de
}

\begin{abstract}
Digitalization is currently the most important driver of economic growth. Inspired by increasing digital networking and smart automation possibilities, omnipresent access technologies and dynamic customer requirements, modern enterprises work more and more on additional and new digital business models. The aim is to exploit potentials for new and especially digital business models much faster and to cope with the resulting challenges. This requires a technical integration of different disciplines, new qualification profiles and new methodical approaches. The paper proposes the aggregation of selected approaches from the areas of digital business model development, capability management and enterprise architecture management as a methodical basis for the training profile of a "Digital Business Architect" and "Digital Innovation and Transformation Process (DITP)".
\end{abstract}

Keywords: Digital Business Modeling, Capability Management, Enterprise Modeling, Enterprise Architecture Management, Digital Business Architect, Small and medium Business

\section{Introduction}

The successful development and integration of digital business models requires a high degree of agility in enterprises. From an economic perspective, agility is only recommendable if the effects of changes in an enterprise can be determined at any point in time [1, 2]. Furthermore, digital business models usually depend on technological innovations and the exploitation of their potential in a way, which creates entirely new products and services and leads to new operational procedures in enterprises or completely redefines the existing ones. This calls for a methodical and technical integration of approaches from different areas facilitating the required changes, such as digital business model management (BMM), capability management (CM) and enterprise architecture management (EAM) [2].

The integration of these issues shape a modern qualification profile $[2,3]$ which we name „Digital Business Architect“ (DBA). The DBA has to have multi-disciplinary expertise and a corresponding method support, the Digital Innovations and Transformation Process (DITP). The latter, in particular, enables the DBA to moderate as part of the business executive team in an enterprise between business management and technology experts in order to support implementing their 
requirements under consideration of an integrative Business-IT-Alignment (iBITA) concepts [2]. The industrial demand for this qualification profile and organizational role showed in different digitalization projects and the experiences collected in these projects $[2,4]$. The new qualification profile should not only enable personnel and students to develop digital business models but also to carry out the planning and implementation of changes and to provide suitable methods to do so. This paper presents first results of work in progress on the DBA qualification profile and the DITP process. The first process version is currently being evaluated in the context of a master thesis at the University of Rostock [5].

An introduction, the research methodology used for the data collection and its analysis as well as the foundations for the (DITP are outlined in section 1. Section 2 discusses the required methods and chapter 3 presents the core activities of DITP. Finally, the results of this work in progress are summarized and an outlook on further research activities is given in the last section.

\subsection{Research Approach}

A literature analysis was conducted to elaborate the theoretical foundations. In general, two methods are used: The „systematic method“ [6] and the snowballing method [7,8], whereas for the initialization of the literature review, we opted the second approach. This procedure should ensure the inclusion of both scientific and journalistic publications. For a first evaluation, a specific scenario was considered in the context of a case study $[9,10]$. The case study was carried out within the frame of a master thesis at the University of Rostock. The aim was to observe version one of the DBA's proposed process model within a start-up environment and then derive new insights for the improvement of its practicability by means of an argumentativedeductive analysis [10-12].

The process was realized according to [11] and consists in the process steps of planning, data collection, analysis and report (figure 1).

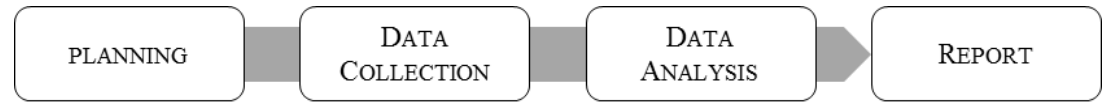

Fig. 1 Process of carrying out a case study according to Göthlich [11].

In the planning phase, we decided on the design of the study as well as on its objective that we defined as follows:

- Explorative goal: Based on the observations and documentations, insights should be obtained und optimization potentials of the DBA's processing should be identified.

- Evaluation goal: The case study serves to validate the process in practice, explicitly considering the scenarios presented in chapter 4 .

During data collection, information determined in the planning phase is continuously documented. For this purpose, survey forms such as interviews, documentations (protocols) and observations were adopted [13]. During analysis, results on the hypotheses elaborated in the planning phase were collected. At the same time, the practicability of the DBA approach was tested and process optimizations 
were demonstrated. The case study is completed with the publication of the results in a report. The report can be published separately, or, like in our case, as part of further studies [11].

\subsection{Fundamentals}

Profound knowledge of the anatomy of business models, necessary capabilities for adaptation or reorganization and the structures affected thereby within or without the enterprise (e.g. processes, IT systems, roles) is a prerequisite for a DBA. As part of new management approaches, they complement established disciplines. To maintain this prerequisite, various techniques, methods and tools are necessary. It also implies that enterprises have to rethink and upgrade the established management approaches to be able to change quickly within a digital environment.

For a successful digital transformation and an integrative approach, knowledge is required in three disciplines: business model management [14-18], capability management [2, 2, 19] and enterprise architecture management [20-23]. All three of them are connected through their respective outputs in the form of models in order to support enterprises with:

- Analysis and documentation of the current company situation comprising business model and the necessary architectural objects such as processes, structures and products,

- Analysis of digital potentials for additional and new value chains,

- Development and concretization of the business strategy for the implementation of digital objectives as well as derivation of the required business capabilities,

- Determining the need for change and planning of the architectures required for the digital transformation,

The approach presented in this work should provide a methodological basis for the role and training profile of the DBA. Its content will focus on the interdisciplinary application of these different management approaches (BMM, CM, EAM) within a procedure model developed for this purpose (figure 2).

\section{Spectrum of Methods and Scenarios}

This section introduces the interaction of the disciplines (BMM, CM, EAM) and presents indications on how to use discipline-specific methods in particular scenarios of digital transformation and thus denote one of the action bases of the DBA.

There already exist scientific books and textbooks for the development of business models and enterprise architecture management providing methods and tools $[14,18$, 23-25]. In the area of capability management that is supposed to act as a link between the disciplines, numerous approaches exist. However, there is only on integrative approach addressing this topic [2]. So far, a higher level procedure for the integrative use of the single disciplines in the form of a process model is not yet available [5]. 
A special feature of the approach presented in this work is the focus on the interaction of available methods of the respective disciplines considering a choice that should be preferably needs-based.

The following scenarios exemplify typical situations in enterprises which require the integrative use of different disciplines and the different possible fields of actions of the DBA:

1. The first scenario is an existing enterprise which is facing new productrelated, customer-related and/or competitive challenges due to digitalization and which needs to react on them promptly.

2. In scenario 2, the main concern is implementing a business concept in a start-up company.

3. Scenario 3 is a company situation in which no urgent need of action regarding a digital transformation is given but in which the company is interested in raising its digital potentials and thus improving their business activities by complementing or expanding it.

The process illustrated in Figure 2 is not only an efficient means to tackle businessmodel and architecture-related problems but to foster communicative improvement as well as the knowledge about the enterprise.

Figure 2 shows the entire digital innovation and transformation process (DITP) as well as the separate process steps required by the DBA.

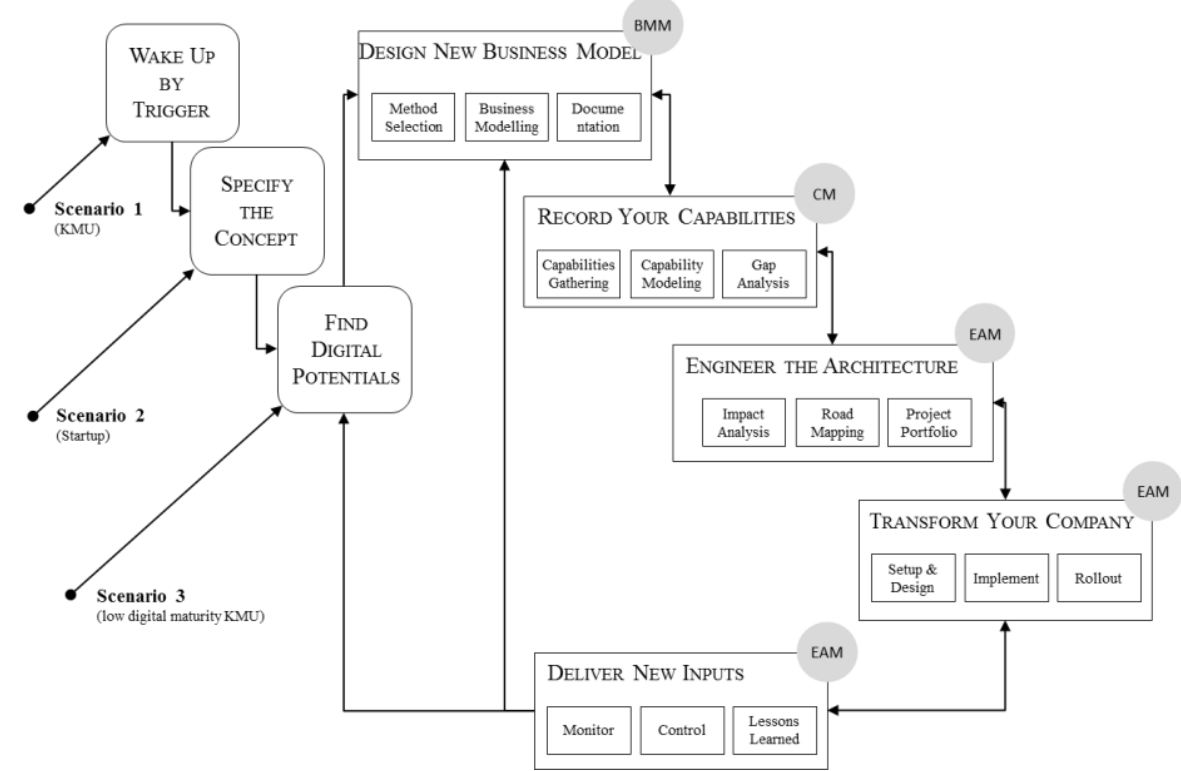

Fig. 2 Digital innovation and transformation process (DITP) including required disciplines.

\section{DITP Procedure Model}

This section outlines the DITP procedure as well as the core competences of the DBA necessary for the development and the implementation of digital business 
models. In section 2, three typical enterprise situations with different starting points for the DITP procedure were presented. In the following, we will only focus on aspects of the second scenario since this scenario already has been studied in detail in a case study company (section 1). The case study carried out was to accompany the realization of a new digital business i.e. the founders of the new enterprise were supported by the DBA and the DITP procedure during the start-up process.

Starting point for the second scenario is the so-called „Specify the Concept" phase in which an existing idea is elaborated with the help of creative methods. This idea should have a clear business purpose. This elaboration follows an idea process that helps identifying and formulating, among others, internal/external factors, requirements and implementation approaches. The process is divided in three activities: DITP1.1 Identification of the idea, DITP1.2 Activation method, DITP1.3 Elaboration of the concept. To provide a common methodological starting point, the activities for the elaboration of the basic idea are carried out by all founders. The competence required of the DBA consists in being able to derive a concept from ideas in a systematic way according to the requirements of the concept, e.g. by applying one of more than 60 existing creativity techniques. The outcome of this phase is a comprehensively documented business concept.

The process step „Find Digital Potentials “ focusses on the analysis of digital trends and building blocks and helps finding possible digital approaches that could be relevant for the business concept. This phase is divided into the activities DITP2.1 Research of digital trends/building blocks, DITP2.2 Evaluation of digital trends/building blocks. Based on the documented business concept, the first activity allows the research of different data sources in order to find digital trends/building blocks such as Gartner Hype Cycle [26], Technology Radar [27], TechTrends [28] und Producthunt [29]. Examples for digital technology building blocks are: Automatisation (Robotik, adaptive manufacture, autonomous vehicles), Digital accesses (social networks, mobility, apps, market places, gesture and voice control) interconnectivity and exchange (broadband, mobile Internet, IoT, Industrie 4.0, Cloud), artificial intelligence (smart cities \& homes, agents \& bots, machine learning), Data (big data, blockchain, predictive maintenance), User Experiences (Wearables, Virtual Reality, context-related individualization).

The founders involved preselect potential digital trends/building blocks for the business model development of the next phase by means of feature or priority evaluations. When a trend/building block is from the list of candidates, we speak of a digital potential, because, from the founding team's perspective, it will support the realization or the improvement of the business idea. This phase has also to be carried out by all founders. It is recommendable but not imperative to involve team members with a high affinity to technology. In this phase, the DBA supports the research of digital trends/building blocks and gives advice on how to use them in possible application scenarios. The outcome of this phase is a technology map with suitable digital potentials that will be considered in the context of the business model development. The accuracy of this map will be specified more precisely later on.

The third phase includes the modelling of the business model „Design New Business Model“. Different approaches can be used for modelling according to personal preferences or the requirements of the project $[14,17,18,25]$. For this purpose, the following activities have to be accomplished: DITP3.1 Choice of 
business modelling approach, DITP3.2 Modelling of the business model, DITP3.3 Visualization of the business model \& documentation. For scenario 2, we selected the business model innovation method according to [14] which is one of the most comprehensive and most detailed approach for the detailed development of business models.

The founding team was convinced by this approach because of its comprehensive methodological support (metamodel, questionnaires, examples) during the different phases of the business model development. The graphical representation of the business model using visualization software is a possibility of documenting the results. Another possibility of documentation is based on the proposed meta model by [14] that can be represented by means of modelling tools. This process step is accounted for by the executive manager who is actively taking part in the specific activities. The DBA plays the implementing role in this process step and supports the choice of the business model approach, the business model development and the choice of suitable documentation software. The outcome of this process is a comprehensive digital business model that serves as basis for the following operationalization activities.

In the process step „Record Your Capabilities“, we will resolve the following question: "What capabilities are needed by our company or our future company in order to implement the developed business model?" As a starting point, the discipline of capability management gaining growing attention in theory and practice will help to answer this question $[1,30]$. At present, capabilities are considered as missing link between business units and IT and therefore support the business IT alignment [2, 31, 32]. For the present phase, we suggest an efficient method (Capability Management Guide) that supports the identification, the structuring and the management of capabilities [2]. In scenario 2, the following activities were carried out in the context within the framework of the Capability Management Guide (CMG): DITP4.1 Collection of required and existing capabilities, DITP4.2 Capability modeling, DITP4.3 Gap analysis and adaptations. The $\mathrm{CMG}$ is based on an integrated capability approach that was developed from different scientific studies. The approach is integrated in a process comprising four building blocks. They propose suitable procedures, concepts and supporting tools derived from specific theoretical and practical applications in order to detect and structure capabilities within the company [2]. The process is accounted by the management team of the start-up. The DBA takes over the executing role during this process step and conducts the four building blocks. In doing so, the DBA integrates the founder and the disciplines in the elaboration of the capabilities catalogue. The outcome of this process is a catalogue describing the required capabilities for the implementation of the business model.

In the phase „Engineer the Architecture“", the future enterprise architecture model is derived and defined by means of the detected capabilities and possibly considering the present architecture. The aim of this phase is to draft an enterprise architecture model (EA) including the required architecture objects and their dependencies in order to obtain a transparent picture about the aspects necessary for the implementation of the business model [33]. The defined capabilities catalogue serves as a basis for the retrieval of required enterprise architecture objects [2]. In this context, we propose the following activities: DITP5.1 Choice of an approach for the impact analysis, DITP5.2 Development of the enterprise architecture including 
roadmap for integration, DITP5.3 Project portfolio for the implementation. For DITP5.1, it is necessary to select a suitable modelling approach and tool. This can be done primarily on the basis of the detected requirements and/or on the basis of existing experiences [33-35]. Since scenario 2 is about an initial EA and with the resources of the founders being limited, they will need an uncomplicated and easy-tolearn method for the modelling. This method, however, has to be able to represent the entire architecture (e.g., processes, IT, roles, resources, objectives). A method that meets these requirements is the 4EM-Method [36]. It describes an approach for a systematic and controlled procedure for the analysis, development and documentation of a company or an organizational unit. The aim is to represent structures and processes incrementally in the form of an EA, whereas the single elements can be already derived from the capabilities of the catalogue.

To complete the elaboration of the enterprise architecture, the specific models have to be documented appropriately. For this purpose, we recommend software tools ranging from simple text programs, spreadsheet applications or graphic programs to comprehensive enterprise architecture modelling and management tools that need to be selected in accordance with the profile of requirements and maturity [33, 37]. Since scenario 2 described a start-up with an uncomplicated approach of enterprise architecture modelling, a single graphical modelling tool was used initially in order to visualize the required dependencies. The DBA plays an implementing role in this process step and supports the choice of the modelling approach according to the requirements as well as the establishment and documentation of the architecture by means of suitable software tools. The outcome of this phase is the enterprise architecture required for the operationalization of the business model.

The way in which the elaborated EA is implemented and the change measures evolving from it are crucial for the success of the enterprise. The phase „Transform Your Company" focusses the activities DITP6.1 Project set up, DITP6.2 Implementation and DITP6.3 Roll out of the EA in the enterprise. The planning of strategic initiatives and/or single projects provides the framework for the following change measures and the implementation of the planned EA. Furthermore, this phase comprises the definition of typical project management activities such as, for instance, the definitions of milestones, supply of information, personnel, escalation handling, implementation and roll out reporting [20]. Here, the recurrence of single parts of the DITP is possible. On the one hand, the successful implementation of an EA depends on the planning already mentioned, but also on the degree of maturity of the EA models - any insufficient degree will become evident during the planning phase of the project and must be increased in an iterative process [35]. On the other hand, the users (e.g. executive board, business developers, line managers) must be convinced of the emerging structures $[20,36]$. In order to obtain a successful roll out as well as an extensive use, we recommend the following procedure: The roll out process should start with a specific change measure within the frame of a pilot project in a selected organizational unit. The project has to prove whether the expected advantages actually occur or rather unexpected challenges emerge. After successful completion of the pilot project, the implemented change measures can be rolled out on additional organizational units or on the entire organization. This procedure can be repeated for further changes and organizational units whereas different organizational unit could be in charge of this. On the basis of the EA and by means of graphical models and 
simulations, different implementation approaches can be tested. The DBA supports the project teams(s) with the implementation. The result of this phase is an operationalized business model based on an EA.

Regarding the fact that enterprises are permanently facing new digital challenges in increasingly shorter time intervals, monitor and control activities must be set up in the enterprise. They control the new digital components of the enterprise architecture and can detect signals for digital changes at an early stage [15]. In this context, one of the most important functions of the phase „Deliver New Inputs“ is to safeguard the digitalization objectives. In order to monitor the quality of short, medium and longterm digitalization objectives within the entire enterprise and the changes related to it, enterprises determine suitable indicators to be sustained by a corresponding data base [18]. Especially usage-oriented, trend and context-related data of introduced digital changes form the basis for new inputs of the DITP. Measuring tests, risk assessments and compliance tests are activities based on indicators that could support the implementation and the evaluation of goals as well as the derivation of new inputs for the procedure based on the collected data. The DBA supports the information needs analysis [38] of the management regarding the definition of appropriate indicators and compiles the required elements of the enterprise architecture.

\section{Conclusion and Outlook}

The successful development and integration of digital business models requires a high degree of agility which is only given economically when the effects of the changes in an enterprise or the development of new enterprises can be determined at any point in time. Basic prerequisites are innovative ideas, knowledge about the development of business models, capabilities necessary for the adaptation or restructuring and the architectures affected within and without the enterprise. To maintain these prerequisites, various methods and tools of different disciplines are necessary. These methods and tools were presented as elements of an integrated procedure of the DBA in this work.

In particular, the DBA profile could be taught to students of universities and higher education institutions, especially in business information systems studies, but also in addition to computer science and economic science. For this purpose, the procedure and its methodological contents in the area of electronic business, business model management, enterprise architecture management and business analysis can be used. But it could also serve for practitioners in enterprises for self-study or as manual and thus demonstrate first possibilities and approaches for the digital transformation. The presented DBA profile and the DITP are currently examined in two additional case studies for scenarion 1 and 3 and will be adapted according to the results.

\section{References}

[1] M. Wißotzki, "Exploring the Nature of Capability Research," in Intelligent Systems Reference Library, vol. 111, Emerging Trends in the Evolution of Service-Oriented and 
Enterprise Architectures, E. El-Sheikh, A. Zimmermann, and L. C. Jain, Eds., Cham: Springer International Publishing, 2016, pp. 179-200.

[2] M. Wißotzki, Capability Management Guide, 1st ed.: Springer Vieweg Research, 2017.

[3] C. Lemke and W. Brenner, Verstehen des digitalen Zeitalters. Berlin [u.a.]: Springer Gabler, 2015.

[4] M. Wißotzki, C. Köpp, and P. Stelzer, "Rollenkonzepte im enterprise architecture management," Lecture Notes in Informatics, vol. 244, pp. 127-138, 2015.

[5] t. Plewka, Die Entwicklung einer Fallstudie zur Integration von digitalen Geschäftsmodellen und Architekturen, 2017.

[6] B. Kitchenham, "Procedures for performing systematic reviews," Keele, UK, Keele University, vol. 33, no. 2004, pp. 1-26, 2004.

[7] B. Sandberg, Wissenschaftlich Arbeiten von Abbildung bis Zitat: Lehr- und Übungsbuch für Bachelor, Master und Promotion, 2nd ed. München: Oldenbourg Wissenschaftsverlag, 2013.

[8] C. Wohlin, "Guidelines for snowballing in systematic literature studies and a replication in software engineering," in EASE 2014: The 18th International Conference on Evaluation and Assessment in Software Engineering : London, May 12th-14th, 2014, New York, New York: Association for Computing Machinery, 2014, pp. 1-10.

[9] T. Wilde and T. Hess, "Methodenspektrum der Wirtschaftsinformatik," 2006.

[10] R. Yin, Case Study Research. [s.1.]: SAGE Publications - BOOKS, 2013.

[11] S. E. Göthlich, "Fallstudien als Forschungsmethode: Plädoyer für einen Methodenpluralismus in der deutschen betriebswirtschaftlichen Forschung," Manuskripte aus den Instituten für Betriebswirtschaftslehre der Universität Kiel, Christian-AlbrechtsUniversität zu Kiel, Institut für Betriebswirtschaftslehre 578, Jan. 2003. [Online] Available: http://EconPapers.repec.org/RePEc:zbw:cauman:578.

[12] E. de Vries, "Epistemology and methodology in case research: a comparison between European and Americans is journals. American IS Journals," Primavera Working Paper, 2004. Dispon $\backslash ’$ ivel em: $<$ is2. 1se. ac. uk/asp/aspecis/20050113. pdf $>$. Acesso em: 25 nov. 2007.[Links], Jan. 2007.

[13] L. Dubé and G. Paré, "Rigor in Information Systems Positivist Case Research: Current Practices, Trends, and Recommendations," MIS Quarterly, vol. 27, no. 4, pp. 597-636, http://www.jstor.org/stable/30036550, 2003.

[14] D. Schallmo, Geschäftsmodelle erfolgreich entwickeln und implementieren: Mit Aufgaben und Kontrollfragen, 1st ed. Berlin [u.a.]: Springer Gabler, 2013.

[15] D. Schallmo, A. Rusnjak, J. Anzengruber, T. Werani, and M. Jünger, Digitale Transformation von Geschäftsmodellen: Grundlagen, Instrumente und Best Practices: Springer Gabler, 2016.

[16] D. R. Schallmo, Jetzt digital transformieren: So gelingt die erfolgreiche Digitale Transformation Ihres Geschäftsmodells. Wiesbaden: Gabler, 2016.

[17] C. Hoffmeister, Digital Business Modelling: Digitale Geschäftsmodelle entwickeln und strategisch verankern. München: Hanser, 2015.

[18] B. W. Wirtz, Electronic Business, 5th ed. Wiesbaden: Springer Fachmedien Wiesbaden $\mathrm{GmbH}, 2016$.

[19] P. Anastasios, "Capability-based planning with TOGAF and ArchiMate," Master Thesis, Business Information Technology School of Management and Governance, University of Twente, Twente, 2014.

[20] F. Ahlemann, Strategic enterprise architecture management: Challenges, best practices, and future developments. Berlin, New York: Springer, 2012.

[21] D. Simon, K. Fischbach, and D. Schoder, "Enterprise architecture management and its role in corporate strategic management," Inf Syst E-Bus Manage, vol. 12, no. 1, pp. 5-42, 2014. 
[22] D. Simon and C. Schmidt, Eds., Business architecture management: Architecting the business for consistency and alignment. Cham: Springer, 2015.

[23] P. Stelzer and M. Wißotzki, Enterprise Architecture Management in kleinen und mittleren Unternehmen - Ein Vorgehensmodell: Wie Business-IT-Alignment im Zeitalter der Digitalisierung auch in KMU gelingen kann, 1st ed. Hamburg: Kovac, Dr. Verlag, 2017.

[24] C. Lemke and W. Brenner, Einführung in die Wirtschaftsinformatik: Band 1: Verstehen des digitalen Zeitalters. Berlin: Springer Gabler, 2015.

[25] A. Osterwalder and Y. Pigneur, Business model generation: A handbook for visionaries, game changers, and challengers. Hoboken, N.J.: Wiley, 2013.

[26] Gartner, Gartner Hype Cycle 2016. [Online] Available: http://www.gartner.com. Accessed on: Jun. 192017.

[27] Thoughtworks, Technology Radar. [Online] Available: https://www.thoughtworks.com/de/radar. Accessed on: Jun. 192017.

[28] Deloitte, Deloitte Tech Trends 2017. [Online] Available: https://www2.deloitte.com/global/en/pages/technology/articles/tech-trends.html. Accessed on: Jun. 192017

[29] Producthunt, Producthunt Protfolio. [Online] Available: https://www.producthunt.com/. Accessed on: Jun. 192017.

[30] T. Offerman, C. J. Stettina, and A. Plaat, "Business Capabilities: A Systematic Literature Review and a Research Agenda,"

[31] L. Greski, "Business capability modeling: Theory \& practice," Architecture \& Governance Magazine, 2009.

[32] P. Loucopoulos et al., "Enterprise Capability Modeling: Concepts, Method, and Application," in 2015 Third International Conference on Enterprise Systems - ES 2015: 14-15 October 2015, Basel, Switzerland : proceedings, Piscataway, NJ, Piscataway, NJ: IEEE, 2015, pp. 66-77.

[33] J. Schekkerman, Enterprise architecture good practices guide: How to manage the enterprise architecture practice. Victoria: Trafford Publ, 2008.

[34] D. Matthes, Enterprise Architecture Frameworks Kompendium: Über 50 Rahmenwerke für das IT-Management. Berlin, Heidelberg: Springer-Verlag Berlin Heidelberg, 2011.

[35] I. Hanschke, Enterprise Architecture Management - einfach und effektiv: Ein praktischer Leitfaden für die Einführung von EAM, 2nd ed. München: Hanser, Carl, 2016.

[36] K. Sandkuhl, J. Stirna, A. Persson, and M. Wißotzki, Enterprise modeling: Tackling business challenges with the 4EM method. Heidelberg: Springer, 2014.

[37] J. Schekkerman, How to survive in the jungle of enterprise architecture frameworks: Creating or choosing an enterprise architecture framework, 3rd ed. Victoria, B.C.: Trafford, 2006.

[38] M. Lundqvist, K. Sandkuhl, T. Levashova, and A. Smirnov, "Context-Driven Information Demand Analysis in Information Logistics and Decision Support Practices," in Workshop on Contexts and Ontologies: Theory, Practice and Applications, Riva del Garda, Italy, 2005. 